\title{
The preference for Europe: Public opinion about European integration since 1952
}

Christopher J. Anderson, Departments of Economics and Politics \& International Studies, University of Warwick, UK.

Jason D. Hecht, Institute for European Studies, Cornell University, USA.

\begin{abstract}
To determine how public opinion matters for the politics of European integration, we need to know what Europeans say about Europe. Yet, despite a proliferation of analyses of public support for Europe, fundamental questions remain. First, does aggregate opinion reflect a single preference for Europe? Second, is the content of opinions similar across countries? Third, have opinions about Europe become more structured over time? Finally, what are the long-term dynamics in opinions about Europe? To answer these questions, we construct a new dataset of historical public opinion since 1952 in France, Germany, Italy, and the United Kingdom. Over the long run, aggregate opinion toward Europe reflects one dominant underlying dimension and its content is similar across countries. We examine the trends in support for Europe.
\end{abstract}

Keywords

European integration, public opinion, EU support.

Corresponding author:

Christopher J. Anderson, Departments of Economics and Politics \& International Studies, University of Warwick, S1.65, Coventry CV4 7AL, UK.

Email: chris.anderson@warwick.ac.uk 
It is commonly assumed that public opinion matters to the process of European integration and to governing the European Union (EU). Journalistic and popular commentary about public sentiment is ubiquitous and often focused on whether support for Europe is high or low, on the rise or on the decline. Yet, despite decades of academic scholarship on public opinion about European integration, institutions, and policies, important conceptual and empirical questions remain. On a conceptual level, researchers have portrayed survey measures of support as a kind of system support or have simply taken them at face value. On an empirical level, more studies have focused on investigating individual-level differences in attitudes toward Europe than on examinng aggregate changes in opinion over time. This imbalance requires attention if we want to understand the politics of the Union, insofar as "[u]seful, and therefore consequential, opinion is aggregate. Politicians care about the views of states, districts, areas, cities, what-have-you [...]. For a politician to pay attention to individual views is to miss the main game" (Stimson, 1991: 12).

To address these gaps, we seek to provide conceptual and empirical grounding for the study of public opinion about Europe. First, we argue that support for integration can be thought of as a simple preference for or against a supra-national Europe. Second, we develop a measure of support based on data collected in France, Germany, Italy, and the United Kingdom (UK) since the earliest days of the European project. Third, we subject this measure to several tests. Our analyses reveal that aggregate opinion is largely unidimensional in nature. Moreover, they show that public opinion in the UK is different from opinion in the other countries, both in level and trajectory. Trends in support for Europe show notable declines in France, Germany, and Italy over the course of several decades, while public opinion in the UK has been relatively stable - albeit at a lower level - when considered over the entire post-war period.

\section{Carts and horses: Public opinion and European integration}

In October 1954, on the heels of the London Nine Power Conference that formally ended the occupation of West Germany and granted it sovereignty and membership in the North Atlantic 
Treaty Organization (NATO), the United States Information Agency (USIA) fielded a public opinion survey in France, Germany, Italy, and the UK to gauge Europeans' attitudes about a variety of topics of interest to American policymakers. Soon after the end of World War II, USIA had begun to monitor Europeans' opinions on various issues, including German re-unification and, as the Cold War was heating up, views about the Soviet Union, Communism, the use of nuclear weapons, and America's role in Europe.

The surveys also included questions about European unification. 1952 had seen the creation of European Coal and Steel Community, and the London Conference had paved the way for the creation of the Western European Union. USIA found that responses to the question "Are you, in general, for or against making efforts toward uniting West Europe?” were overwhelmingly positive: $82 \%$ of West Germans embraced the idea, as did $78 \%$ of British respondents. Even in the countries that were slightly less enthusiastic (Italy and France), strong majorities (63\%) were in favor of the idea. When asked whether they liked the idea of creating a European government to which national governments would delegate their powers, $78 \%$ of Germans were in favor; even the lowest level of support among national publics, found in the UK and France, came in at 55 and 56\%, respectively. Clearly, the idea of a unified Europe was viewed positively across the major European states.

(Figure 1 here)

As the 1950s continued, so did the USIA's program of surveying European publics. While primarily focused on Europeans' views about the United States (U.S.) and conflict with the Soviet Union, the surveys also consistently asked people's opinions about different aspects of European integration, with questions about unifying Europe and membership in European institutions (European Economic Community, Euratom) providing a common thread. Across countries and over time, a recognizable pattern to what people thought about Europe began to form, with German respondents expressing more positive views, and majorities across all countries in favor of the 
European project. Moreover, as Figure 2 shows, a common trend seemed to emerge, with support declining across all four countries in 1955 only to recover in 1956.

(Figure 2 here)

What these patterns mean and how they matter have been long-standing questions in the debate over the integration process and the functioning of European institutions. Two stylized positions have dominated this debate. The earliest of these argued that public opinion was irrelevant to the elite-driven nature of the politics involved (Haas, 1968; see also Gaubatz, 1995). This perspective saw European integration as a matter of international relations, where domestic publics mattered little.

Most scholarship has disagreed with these early functionalist perspectives. Transnationalist scholars, for instance, emphasized the importance of a "sense of community" for building a united Europe (Deutsch, et al. 1957; Etzioni, 1965; see also Eichenberg and Dalton, 1993), and scholars of international relations argued that opinion mattered through its influence on governments' preferences (Moravcsik, 1998). A consensus emerged that public opinion indeed matters to the integration process because it both constrains elites and can be mobilized by them (Carrubba, 2001; Franklin and Wlezien, 1997; Gabel and Scheve, 2007; Schmitt and Thomassen, 2000; Toshkov, 2011; Wessels, 1995).

A second, related consensus has centered on the apparent structural break in support for the EU after the signing of the Maastricht Treaty in 1992 and the treaty's subsequent rejection in a referendum in Denmark. Across a number of member states, support peaked around this time. The subsequent downturn has been interpreted as signalling both the end of the so-called "permissive consensus" between elites forging greater integration and publics paying scant attention, as well as the beginning of a more contested Europe composed of more disagreeable publics (Down and Wilson, 2008; Eichenberg and Dalton, 2007). 
These debates regarding the role of public opinion in the European integration process or in governing the EU are interesting, nuanced, and important. They also risk putting the cart before the horse. While commentary about opinions toward "Europe" is pervasive, studies that seek to measure and track long-term trends in public sentiment have been less common (for exceptions, see Anderson and Kaltenthaler, 1996; Bølstad, 2015; Eichenberg and Dalton, 1993, 2007; Inglehart and Rabier, 1978; Inglehart and Reif, 1991; Toshkov, 2011). This is problematic, for two reasons. First, in order to know whether or how public opinion matters, we need to establish exactly what the public is telling pollsters. Second, it is difficult to know whether public support is high or low if we lack benchmarks based on its evolution over extended periods of time. Thus, we need to, first, understand how people respond to questions about Europe; second, we need to establish their empirical content and diagnose their dynamic properties.

\section{Conceptualizing and measuring support for Europe: A historical perspective}

To date, studies of the dynamics of aggregate support for Europe have taken a broadly similar approach with regard to conceptualization and measurement. Typically, this has involved the following steps: to define theoretically that the variable of interest is support for Europe; to suggest that this is a latent variable that is not observed directly; and to further assume that answers to the particular survey item are observed as various thresholds to the unobserved latent variable are crossed (e.g. Anderson and Kaltenthaler, 1996; Bølstad, 2015; Dalton and Duval, 1986; Eichenberg and Dalton, 1993, 2007; Gabel, 1998; Gabel and Palmer, 1995; Inglehart and Reif, 1991; Janssen, 1991; Norris, 1999; Toshkov, 2011; Wessels, 2007).

This approach is simple but potentially problematic. As Hobolt and De Vries note, "[j]ust as most studies have paid relatively little attention to the conceptualization of support for European integration, the precise measurement of public attitudes toward European integration has also received somewhat limited consideration" (Hobolt and De Vries, 2016: 416). To the extent that they have discussed conceptualization and measurement, researchers have typically appealed to 
face validity or have relied on Easton's categories of diffuse and specific support when justifying the use of survey items (Easton, 1965; Lindberg and Scheingold, 1970). The trouble with the former approach is that alternative tests of validity have received limited attention. The trouble with the latter is that it may overly stretch the original concept (Goertz, 2006; Sartori, 1970).

In retrospect, the advent of the Eurobarometer surveys in the 1970s may have contributed to these practices. While these surveys became an indispensable resource for students of European public opinion and political behavior, they also had unintended consequences for scholarship on support for Europe. First, by providing a set of readily-available indicators that, at first glance, seemed tailor-made to measure support "[ [...] these expanding data sets were used to achieve greater analytical precision and more substantial empirical evidence [...]. However in doing so, the variables of interest were adjusted to fit the needs of the analysis [...]" (Loveless and Rohrschneider, 2011: 8). Put simply, survey items were often "retrofitted" to suit the analysis.

Moreover, because the Eurobarometer was among the few survey projects that provided researchers with access to high quality, cross-national, individual-level data, scholars gravitated toward explaining individual-level and cross-sectional differences, rather than aggregate-level and intertemporal ones. As a consequence

"Studies have employed a variety of measures to capture the empirical dynamics of support, such as trust in EU institutions, support for membership, or desired speed of integration. Most scholars rely on the Eurobarometer surveys because these constitute the only data source that allows for cross-national and longitudinal comparisons. One problematic issue, however, is that several questions have been reworded or excluded from the surveys, and hence very few questions cover the entire period since the early 1970s. As a result, there is often a trade-off between analyses that rely on one or a small set of items to measure support over time and a cross-sectional analysis of various dimensions of support captured at a single point in time" (Hobolt and De Vries, 2016: 416-417).

This trade-off may not be inevitable if we are able to identify a way to conceptualize and then measure support for Europe, and do so over extended periods of historical time. On a conceptual level, we posit that the nature of the European project and the history of European politics in the post-war period are such that it is sensible to presume that there is only one object of 
support in the public mind in the early post-war decades. That is, rather than starting with the presumption of separable dimensions of attitudes toward European political objects, we assume one underlying (and possibly rather diffuse) predisposition for or against Europe.

We define this general attitude of "support (or 'preference') for European integration" as a positive orientation toward the object of European integration, as embodied in the actual process and institutions of the European Union and its predecessor organizations, starting with the Treaty of Paris. We use "support" and "preference" for European integration synonymously, with both intended to indicate a positive attitude. Similarly, we view both opposition and skepticisim as manifestations of a preference against integration (see also Hooghe and Marks, 2007). Above all, defined positively or negatively, support for, or opposition to, Europe is different from Eastonian system support.

Our definition has empirical implications. At a basic level, it implies that attitudes people hold toward Europe are not well structured. The limited research that exists on the individual-level structure of Europe-related attitudes supports this view. Specifically, a small number of factor analyses of data collected at single points in time in the 1980s and 1990s have shown that individual-level support indicators load extremely highly on a single dimension (Gabel, 1998; Gabel and Anderson, 2002; see also McLaren, 2006). ${ }^{1}$ Even a basic factor analysis conducted fifty years ago on French and West German surveys from the 1950s shows that attitudes toward unifying Europe and membership in a European Confederation loaded extremely highly, and were clearly separate from factors such as Russia, the Cold War, or Security (Puchala, 1968). ${ }^{2}$ Separately, research has shown that citizens use heuristics to form opinions about Europe, rather than evaluating Europe on its own, specific terms (Pannico, 2017; see also Anderson, 1998; Hooghe and Marks, 2005).

At the aggregate level, we expect that the early integration efforts that created the European Coal and Steel Community and then the European Economic Communities initiated a process that is reflected in the pattern of opinions across European publics. Because this process evolved for 
several decades before the EU existed as the differentiated political system we know today, there may be significant path dependency in aggregate support patterns. At a minimum, it suggests the possibility that aggregate opinion about Europe is anchored differently in each country and evolves gradually from there - or, to use statistical language, that opinions may vary in the short- and medium-term as a function of the politics and economics of European integration, but that there are strong intercept and socialization effects over the very long-term.

The idea that the formation and trajectory of attitudes about Europe are endogenous to the particular time and conditions surrounding entry into the European project is also consistent with what we know about countries' decisions to formally join the integration process (for an example, see Diez-Medrano, 2003). Not only were the publics in countries that joined the Union early more supportive of the integration process than those that chose to stay out or join later, but also, by joining, countries started on and then travelled down the path of integration from different starting points. Publics' preferences regarding Europe emanate from these unique historical experiences, with membership and participation in European politics creating distinct approaches to "Europe."

\section{Measuring historical public opinion}

In simple terms, then, there are two ways for people to respond to survey questions about Europe. The first is that they have separable and separate ways of thinking about Europe. The second is that people respond either with general, not to say vague, considerations in mind. The latter would be equivalent to a "latent variable underlying the observed responses to survey questions [...]. It would be a general response to government, not domain specific" (Stimson, 2005: 4). Identifying such a latent variable, if indeed it exists, requires sample surveys. Ideally, these would ask identical questions, covering all conceivable dimensions of support, in all member states and for the entire period since the inception of the European Coal and Steel Community.

While there is no set of surveys that meets all of these conditions, we were able to collect historical opinion data measuring various aspects of support for Europe from four survey projects 
conducted in Europe since World War II. These span the period from the formal inception of the integration project in 1952 to 2017 in several of the original member states (France, Germany, and Italy) and the United Kingdom.

\section{Surveys used}

The earliest usable surveys were those conducted by the United States Information Agency in several of the original members of the European Coal and Steel Community (France, Germany, and Italy) and the United Kingdom beginning in 1952. These surveys, collected intermittently until 1969, constitute the first effort to collect opinion data about politics in Europe on a cross-national basis (for a detailed description, see Merritt and Puchala, 1968). Importantly for our purposes, some questions were repeated in multiple surveys and provide insight into changes in Western European perspectives on public affairs (see also Isernia, 2008).

Concurrently to the USIA, in 1962, the European Commission began polling publics in France, Germany, and the Benelux countries through the so-called "Attitudes Toward Europe" surveys, followed by a set of surveys referred to as the "European Communities Studies", also conducted irregularly from 1970 until 1973. At that point, the Commission decided to institute the Eurobarometer surveys to collect opinion data in applicant and member states of today's European Union (at least) twice a year. Combined, these sources provide us with public opinion data collected in several hundred national surveys in France, Germany, Italy, and the UK based on interviews with about 450,000 individual respondents over the entire period of European integration from 1952 to 2017 (see the Online appendix for details on measures and data sources).

\section{Data and measures}

For our analyses, we rely on those questions that were asked in at least 10 surveys over a period spanning at least 10 years. These include 14 questions about various aspects of the integration process and the European Union (or its predecessor organizations). Importantly, these 
include questions that tap into different dimensions of support and the integration process. They include measures of undifferentiated support objects - support for unifying Europe and optimism about the future of the EU, for instance - as well as specific ones, including whether people think their country has benefitted from membership, whether EU democracy works well, or whether they trust the European Parliament and Court of Justice.

Researchers have used some of these questions widely over the years - for instance, the questions about unifying Europe and membership - but not all have been asked in all countries in every survey, and some, like trust in the European Central Bank, were asked for only relatively brief periods of time. This means that these time series form a patchwork quilt of survey items that cover the entire history of the integration project, but also that there is not a single question covering the entire period since 1952 (the questions and the time periods covered by them are shown in Table A.1. in the Online appendix).

\section{Analysis}

To make use of these disparate sources of historical opinion series, we need a way of knitting them together and identifying the common dynamic elements from multiple indicators across surveys. To do so, we rely on Stimson's dyad ratios algorithm, which has been widely used by students of public opinion in a variety of domains (Stimson, 1999, 2004). The algorithm extracts the common dynamic elements by focusing on the relative changes within an item rather than their absolute values. It is thus analogous to conducting a factor analysis on time series data. It calculates how the marginals for each question asked in each survey change over time, extracts the latent dimensions underlying the shared patterns of variance across these changes, and produces the relevant number of series of public opinion data.

We proceed in several steps. First, we estimate the extent to which attitudes about Europe share an underlying, latent construct over time. Second, we examine its content and generate measures of support for integration for the countries investigated here. We then investigate their 
evolution since 1952 and examine their trajectories since the beginning of the integration project. Finally, we examine whether the structural break implied by the literature on European integration is reflected in the data and discuss the potential implications of trends in the data for the politics of EU governance and integration.

\section{One dimension or two?}

To establish the dimensionality of support, we start by analyzing two periods: first, one that comprises all surveys we have assembled for the entire history of integration between 1952 and 2017; second, the period that includes all surveys conducted by the Eurobarometer since 1973. ${ }^{3}$ To see if the items separate into recognizable factors indicating diffuse or specific constructs, or perhaps factors measuring support for institutions versus the process of integration, we instructed the algorithm to look for two dimensions (for more information on the analyses, see the Online appendix). Table 1 reports the Eigenvalue estimates for both periods, as well as the proportions of variance in the latent variable explained by each factor.

[Table 1 about here]

The results indicate a dominant first dimension in all four countries. Eigenvalues are always greater than 1 on the first dimension, ranging between 2.54 (UK) and 3.21 (Italy) for the entire 1952-2017 period and 3.64 (UK) and 4.34 (Italy) for the 1973-2017 period, with France and Germany in-between. Equally important, Eigenvalue estimates for a possible second factor are lower than 1 on the second dimension in six of the eight analyses. While the highest Eigenvalue estimates on the second dimension reach 1.01 and 1.05 in France and Italy, respectively, in the 1973-2017 period, the estimates for the first dimension are more than four times as large. Taken together, these results suggest at best a minor role for a second dimension. 
This is also reflected in the amount of variance explained by each of the factors. Results show that the first factor explains most of the variance in the support series in all four countries, accounting for somewhere between $75 \%$ of the variance in Italy to $61 \%$ in the UK for the 1952 2017 period. Similarly, it explains between $72.5 \%$ (Italy) and 62\% (UK) for the four-plus decades since 1973, with France and Germany ranging between 66 and 71\%. Thus, the first factors explain between two thirds and three fourths of the variance in the underlying construct - numbers that compare favorably to other applications of the algorithm in public opinion research.

Again, there is a hint of a second dimension in the percentages of the variance explained by each factor, with the second factor accounting for a small proportion of the variance in aggregate opinion. The variance explained by the second factor ranges between 10\% (Germany 1973-2017) and 19\% (UK, 1952-2017). Perhaps equally noteworthy, the patterns of results are uniform across the four countries, with one dominant first dimension accounting for the lion's share of variation in the underlying opinion series.

Taken together, the patterns of Eigenvalues and variance explained lead to the baseline inference that, when considered over the long run of post-war history, and regardless of whether we use the entire period or solely the period since the inception of the Eurobarometer, public support for Europe is essentially one-dimensional. Moreover, despite some variations in Eigenvalues across countries, this pattern holds in every country investigated here. This lends consistent support to the notion that the preference for Europe that lies at the core of public opinion is unidimensional.

\section{The content of aggregate opinion across countries}

What, then, is the substantive content of this core dimension, and how much commonality is there in factor loadings across countries? Put another way: while there may be one core dimension of aggregate support, does this mean that the content of the underlying latent construct series is similar across countries? To answer these questions, we report the factor loadings for the 
1952-2017 period in Figure 3 (those for the 1973-2017 period are largely identical and shown in the Online appendix).

They reveal that around 10 of the 14 indicators load extremely highly in each of the four countries, with several of them exceeding 0.90. Thus, the first inference to be drawn from the results is that, collectively, these items capture the core support dimension well and encompass a wide variety of reported attitudes. Moreover, there is a common set of items that load extremely highly in all of the countries investigated here. Using a 0.7 loading as a cut-off, these items include support for EU membership, assessments of the benefits from membership, regret if the EU were scrapped, appraisal of the EU's image, and trust in the European Parliament, the European Commission, and the European Central Bank. These findings suggest that the core preference for Europe is about membership in the EU and benefits from it, alongside judgments about the trustworthiness of key institutions and a general view of the EU's image.

[Figure 3 about here]

Beyond this shared pattern, two items load highly in some but not all countries. Optimism about the future of the EU is a key component of the preference for Europe in France, Germany, and Italy - with factor loadings in excess of 0.9 in Italy and Germany - but not the UK, where the factor loading is also positive but only about half the size (0.47). The factor for the item measuring people's satisfaction with the performance of EU democracy is positive in all four countries, but quite low in France and Italy $(\sim 0.3)$ and the UK (0.48), while it loads highly in Germany (0.77).

Finally and in contrast, the items measuring the desired speed of integration and attachment to Europe show less consistent performance across countries and contribute to the preference for Europe only in some member states. Attachment to Europe loads positively and extremely highly in Italy (0.92), but has a sizable and negative loading in Germany (-.58), is essentially zero in France, and middling and positive in the UK (0.44). Interestingly, the desired speed of integration seems to 
have the least in common with the underlying preference for Europe. The factor loading is modestly negative in one country (France), not significantly greater than zero in another (UK), and only has a very modest and positive loading in Germany and Italy ( 0.31 and 0.16 , respectively).

Thus, a number of common core items form the basis of the preference for Europe, with some additional features rounding out the national factors - for example, with attachment to Europe and optimism about Europe mattering a great deal in Italy. Taken together, we find that the underlying preference is not simply an amalgam of all the different questions related to Europe. Importantly, too, not all items load strongly on the underlying factor, suggesting that satisfaction with EU democracy or the desired speed of integration do not contribute much to the dominant dimension underlying a preference for Europe.

We draw the following conclusions: First, the data reveal a single dominant dimension underlying aggregate opinions about Europe; second, support is captured by a broad set of indicators and consistently so; third, while there are cross-national differences in the factor loadings, these are less pronounced than the commonality in loadings in each of the countries. ${ }^{4}$ While this is the case when we pool all data for the entire period or examine only the Eurobarometer data, these results cannot speak to the issue of whether the underlying structure has changed over time, and especially since the signing of the Treaty of Maastricht. This is a question we turn to next.

\section{The Maastricht Treaty: A structural break?}

To examine whether the structure of support has changed over time, we estimated the extent to which the set of indicators loads differently before and after 1992. In particular, we are interested in whether public opinion has become more differentiated following the growth and evolution of the integration process. Specific and generic attitudes may well have been closely aligned during the early decades of integration. Over time however, and to the extent that the European political system has become differentiated, the structure of aggregate opinions may have become more differentiated as well. 
To address this question, we repeated the analysis undertaken for the entire period separately for the pre- and post-Maastricht periods; the results are shown in Table 2. They confirm a single dominant dimension before and after Maastricht. While the second factor achieves higher Eigenvalues after 1992, so does the first dimension, with all Eigenvalues consistently higher in the post-1992 period. However, despite this increase in Eigenvalues across the board, the estimates for the second dimension are always significantly lower than for the first dimension. We interpret this to indicate that the pattern of results for the pre- and post-Maastricht periods points to a dominant first dimension and a weaker or non-existent second dimension. ${ }^{5}$

To provide further context for this result, it is instructive to consider the Eigenvalue estimates alongside the variance explained by each dimension. The results show that the variance explained by the first dimension is largely similar in Italy and Germany in both periods, while it is reduced in France and the UK after 1992. Further investigation of the factor loadings in these countries did not reveal any patterns that would indicate significant changes in the factor structure before and after Maastricht. Thus, there is only limited evidence that the factor structure changed after 1992. At the same time, we do not see strong evidence that Maastricht fundamentally changed the underlying core of aggregate opinions about Europe.

[Table 2 about here]

\section{The dynamics of support over the long run}

Based on the factor loadings discussed above, the dyad ratios algorithm generates a measure of support for Europe in each of the countries. This measure represents the dynamics of the single latent construct over time, and it therefore takes into account the country-specific loadings reported above. Below, we investigate its trajectory since $1952 .^{6}$ 


\section{Seeing the forest for the trees}

To evaluate the evolution of support, we start with a visual inspection of the series. Figure 4 plots support between 1952 and 2017 for all countries jointly; to further identify specific national patterns, we also plot each country's series separately (Figure 5). The graphs show several noteworthy patterns. First, Figure 4 demonstrates that long-term support levels are high in three of the four countries we investigate, with average support in the mid-60s (France: 65.4, Germany: 66.5) and even 70 (Italy: 70.1). The one obvious exception is the UK, with a long-run average of 44.5. Thus, averaged over the span of six decades, the Italians were the biggest Euro-enthusiasts, with France and Germany not too far behind, while the UK's scores on the preference for Europe were never consistently positive.

A second noticeable feature of the series is that, for several decades following World War II and up until the late 1980s support levels fluctuate at high levels around their long-standing means in France and Germany; this is most obvious in the country-by-country graphs shown in Figure 5. Similarly, Italians rapidly discovered their taste for Europe in the 1950s and by the mid1960s, their support trajectory, too, is locked into a high and steady level of support very similar to France and Germany (see also Isernia, 2008).

However, the trends also reveal significant changes in support in France, Germany, and Italy over the past three decades, as historically high levels of support have gradually trended downward to a point where positive and negative opinions are virtually tied. In fact, France, Germany, and Italy all exhibited peaks in support in the mid-1960s and then again, at a slightly lower level, in the late 1980s (Italy and France) and early 1990s (Germany), after which it declined. Interestingly, support in Germany picked up again in the late 1990s and has remained relatively stable, while support in France and Italy has been on a continued path of long-term decline.

We confirmed these conjectures with the help of supplementary regression analyses that estimated support as a function of linear and curvilinear trend variables (year and year squared). 
These indicate that the best functional form for the French and Italian series includes highly significant linear and curvilinear coefficients; the coefficient of determination shows that they jointly explain $81 \%$ and $83 \%$ of the variance in the series. In contrast, the best functional form for the German series includes a simple linear and negative trend, which accounts for $71 \%$ of the variation in the series (a regression including a curvilinear term does not increase the R-squared and renders both coefficients insignificant).

UK public opinion offers a very different picture (see also Bølstad, 2015). After an initial high of support for a unified Europe in the mid-1950s, British enthusiasm went on the wane for well over two decades, punctured by temporary and minor rallies in the mid-1960s and, at a lower level, the mid-1970s. After hitting the nadir in 1980 and 1981, support climbed steadily through the 1980s into the early 1990s, after which it went on a slide again, alongside the other countries, only to accelerate between 2007 and 2013. Ironically, in light of the country's decision to exit the EU, UK opinion toward Europe has recovered significantly since 2013 and to levels not too far below those of France and Italy. Clearly, though, the dynamics of UK opinion stand apart from the other major European states: it has displayed consistently lower levels of support since the 1950s, and has been consistently more prone to fluctuation than support in France, Germany, and Italy. Thus, UK opinion is perhaps best described as ambivalent in the long run and more volatile in the short-term.

[Figures 4 and 5 about here]

Combined with the factor loadings discussed above, the dynamics of support across the four countries suggest that there is a basic core of support that is differentiated by country rather than time period. That is, while the content of the preference for Europe may not have changed significantly over time and is similar across countries, there are distinct country-specific trends in its trajectories over time. To use statistical language, the core of Britain's preference for Europe is not fundamentally different from France's, Germany's, and Italy's, but its intercept has been 
consistently lower over the last six decades. This finding speaks to the importance of recognizing that inferences about whether support is high or low, or whether it has changed appreciably over time, are potentially subject to selection bias. Thus, using data from 1973 to 1993, Anderson and Kaltenthaler (1996) report, for example, that support had increased over time, while Down and Wilson (2008) and Eichenberg and Dalton (2007) seek to explain the decline in support in the 1990s. What one sees indeed depends on when one looks; taking the long historical view helps to clarify the baselines for each nation's level of support.

Further formal analyses of the dynamic properties of the EU support time-series - and in particular whether the series are stationary - provide mixed results (see the Online appendix). Augmented Dickey-Fuller tests indicate that the UK series is stationary, whereas those in the other three countries are not. The results from further Kwiatkowski, Phillips, Schmidt, and Shin (KPSS) tests corroborate this conclusion for France and Italy. In these countries, stationarity is clearly rejected; turned around, it confirms that the Italian and French series do not have a constant mean and variance over the period we investigate, a fact that is reflected in the downward trend since the 1980s that shows little sign of abating. In contrast, the results for the German and British support series are more equivocal, though the UK comes closest to exhibiting a level of support that acts like an anchor to which opinion inevitably returns after moving up or down over time.

\section{Discussion}

The scholarly literature on the role of public opinion in the European integration process is divided between those who believe that public support for Europe matters, those who believe it does not, and those who think it can, might, or should. It is difficult to adjudicate among these competing perspectives absent a more systematic conceptualization of support for Europe or when extensive knowledge about its dynamics is in relatively short supply. To help close these gaps, we developed a conceptualization of support for Europe as unidimensional, positing that a more appropriate model of the survey response presumes one general belief about Europe, rather than a 
set of domain-specific ones. We subsequently examined the utility of this conceptualization of support with the help of data collected in four member states of the European Union.

Capitalizing on an original dataset of survey questions related to support for integration since 1952, we investigated the nature of the underlying construct - support for integration - over the entire time period of integration since the Treaty of Paris. The results indicate that support is best characterized as a unidimensional construct, and that this support construct has similar characteristics across countries. Based on these analyses, we constructed country-level time series of public support for integration and examined its trajectory over the past 65 years.

We find that support fluctuates around a steady long-term mean in one country: the UK. In another two (France and Italy), support for Europe approaches an inverted U-shape over the historical long run: support rises in the 1950s and 1960s, plateaus in the 1970s and 1980s, and then starts a steady decline in the 1990s. In the German case, we observe high levels of support throughout the 1950s and 1960s, followed by a very gradual long-term decline since the 1970 s to what looks to be a relatively stable, but lower, level of support in the 2000s.

These analyses have empirical and theoretical implications. On an empirical level, knowing whether support is primarily unidimensional is important for making sense of the mountains of public opinion data about Europe accumulated since the end of World War II. Among others, it is good news for existing scholarship, as it suggests the partial adequacy of using different (single) survey questions as indicators of support, so long as these are treated as incomplete measures of a larger underlying syndrome and are not taken too literally. In particular, the indicators identified as loading highly in Figure 3 can all give a good, but incomplete indication of support. These include the most commonly used survey measures like membership in the European Union or benefits from it, but also less commonly used items such as people's sense of the EU's image or trust in key EU institutions.

In addition, by amalgamating various support measures, we now have a method for comparing measures of support today to support thirty, forty, or fifty years ago, and it would be 
useful to produce additional series for other countries to potentially confirm these results and expand the universe of member states that can be compared and examined. Our approach thus offers a way to construct one consistent measure that can be extended into the present time with every new wave of the Eurobarometer. This opens the possibility of examining the relationship between public opinion and the process of integration over the long historical run and across member states - a question that previously has been investigated with a shorter time series and single item support indicators (e.g. Bølstad, 2015; Franklin and Wlezien, 1997; Toshkov, 2011).

This also would provide a broader and longer set of data points that could be used to investigate the question of whether there is a "Europe-wide European mood". Based on the conventional membership question, a study by Bølstad (2015) has already provided evidence that the core EU countries - which include France, Germany, and Italy - follow one trend, while others on the periphery - the main one being the UK - follow a different pattern of support for Europe. Further analysis of co-movement in public opinion across member states may help shed light on whether a European demos is emerging.

There are several potential limitations to our analyses and results. In particular, there may be a trade-off between gauging opinion over a longer historical period on one hand - one of our primary goals in this paper - and achieving measurement and estimation precision on the other. Our dataset includes fewer items in the pre-Eurobarometer period, and this may produce a bias in favor of a single dimension. At the same time, the smaller the number of items used in the analysis, the poorer may be our ability to capture the underlying construct reliably. If reliability is compromised, our results that include the earlier periods should be less well behaved.

In the end, there is little that can be done to the measurement and reliability issues directly because we are limited by the historical data available to us. However, to the extent that earlier and later surveys move together, we can be more certain that these items jointly capture similar things. Our results indicate that they do, with items available during the earliest period among the highestloading ones across the different time periods. In addition, the shorter period (1973-2017) can act as 
a check on the robustness of the results for the entire 1952-2017 time series. The analysis of the subset produces results that are largely similar in terms of demonstrating a dominant first dimension; future research should investigate the trade-off between precision and dimensionality of support further.

Another limitation has to do with our conceptualization and the focus on measures that can be taken to indicate support for "Europe," the European idea, and EU political system, or using only indicators that are included in a minimum of 10 surveys over at least a decade. As such, we ignore potentially interesting dimensions of support; for example, more specific or policy-related questions about the scope of a European government relative to member states. Nor did we investigate whether the support measures used in the analysis are more likely to tap into what so-called "relative" support (see e.g. Franklin and Wlezien, 1997, Soroka and Wlezien, 2010). To the extent that people's opinions about the desired speed of integration indicate a relative rather than absolute preference, the item's loading (or lack thereof, see Figure 3) might suggest that the dominant dimension taps into people's absolute preference for Europe.

Theoretically, our analyses set the stage for mapping out a better understanding of the role public opinion plays in the integration process. The nature of support documented above - when combined with high levels of support - is consistent with the original meaning of the "permissive consensus" notion derived from Key's (1961) idea of a "permissive opinion distribution". Like ours, Key's formulation of aggregate support patterns did not presuppose an indifferent public or a particular kind of support, but a public where the plurality was generally supportive of a set of policies (see also Sinnott, 1995). This idea is virtually identical to what Stimson (1991) has called a "zone of acquiescence" - where the public will accept a range of specific outcomes.

Our results indicate that such a zone of acquiescence has never really existed in Britain, though there it has been present in the other member states examined here for much of the time since World War II. This is consistent with the history of integration; it would also help provide one explanation for Brexit originating in public support, or lack thereof. As our results show, with brief 
historical exceptions - most notably the 1950s and early 1990s - Britons consistently have been less enthusiastic about Europe, possibly due to a weak sense of European identity (Evans, Carl, and Dennison, 2018). At the same time, this consensus may be fraying even in stalwart member states like France and Italy where support has been eroding and has yet to show signs of plateauing.

In the end, then, if we want to establish more conclusively whether public opinion about Europe "matters", our reconceptualized measure of support - available for a sufficient number of countries and over a sufficient length of time - provides an important piece of the puzzle. In future analyses, it would be important to focus on support for integration as an independent variable to explain political outcomes at national and European levels. Knowing what support for Europe is and how it works is only the first but critical step in that direction. 


\section{Notes}

${ }^{1}$ Gabel's (1998) work is the most detailed and thorough. He posits and seeks to establish construct validity of an Eastonian conceptualization of support with the help of individual-level survey responses to five questions asked in the October 1985 Eurobarometer survey in the then 10 member states of the European Community (EC). Gabel's results show that all variables load highly on the first dimension. However, he also reports that a two-dimensional model that allows for the two factors to be correlated fits the data better than a simple one-dimensional model (using BentlerBonnet fit indices as the deciding criterion). He concludes that his single factor (uni-dimensional) model is less appropriate for measuring support for European integration than a two-dimensional model.

${ }^{2}$ See also McLaren, 2006, Chapter 2. Using the Mannheim cumulative Eurobarometer trend file, McLaren shows that support for unification and EU membership are highly related across all member states; using the two Eurobarometer surveys from 2000, she shows that support for unification and people's preference for the EU are as highly correlated as support for membership and support for unification.

${ }^{3}$ By analyzing these two sets of time series, we sought to examine whether results were sensitive to the inclusion of data from the 1950s and 1960s, a period during which fewer surveys were conducted and the potential for finding evidence of only one dimension was greatest.

${ }^{4}$ Only two of the second dimensions reach Eigenvalues that suggest some kind of coherence $(>1)$. Closer inspection of the loadings for these two cases (France and Italy 1973-2017) indicates that these loadings are essentially reproductions of the first dimension. Thus, we do not attribute separate, or separable, theoretical or empirical meaning to these second dimensions.

${ }^{5}$ The increase in Eigenvalues for the first and the second dimensions may be due to the richer array of data and perhaps more reliable measurement of the latent variable by multiple indicators in the later decades, which strengthens the Wcalc algorithm's ability to identify the underlying mood construct.

${ }^{6}$ Because the underlying survey items reflect the ratios of the percent of respondents providing a supportive answer over the total of positive and negative responses, it ranges from 0 to 100 . We multiplied the ratio by 100 for ease of interpretation. Higher values indicate more supportive attitudes and are interpretable as the percentage of positive opinions relative to all directional (positive plus negative) ones. 


\section{References}

Anderson CJ (1998) "When In Doubt, Use Proxies: Attitudes Toward Domestic Politics and Support for European Integration.” Comparative Political Studies 31 (5): 569-601.

Anderson CJ and Kaltenthaler K (1996) "The Dynamics of Public Opinion Toward European Integration, 1973-1993.” European Journal of International Relations 2 (2): 175-99.

Bølstad J (2015) "Dynamics of European Integration: Public Opinion in the Core and Periphery." European Union Politics 16 (1): 23-44.

Carrubba CJ (2001) "The Electoral Connection in European Union Politics." Journal of Politics 63 (1): $141-58$.

Dalton, RJ, and Duval R (1986) "The Political Environment and Foreign Policy Opinions: British Attitudes toward European Integration” British Journal of Political Science 6 (1): 113-34.

Deutsch K, Burrell SA, Kann Lee Jr M, Lichterman M, Lindgren RE, Loewenheim FL, and Van Wagenen RW (1957) Political Community and the North Atlantic Area: International Organization in the Light of Historical Experience. Princeton: Princeton University Press.

Diez Medrano, J (2003) Framing Europe: Attitudes to European Integration in Germany, Spain, and the United Kingdom. Princeton, NJ: Princeton University Press.

Down I and Wilson C (2008) 'From 'Permissive Consensus' to 'Constraining Dissensus': A Polarizing Union?" Acta Politica 43: 26-49.

Easton D (1965) A Systems Analysis of Political Life. New York: John Wiley.

Eichenberg R and Dalton RJ (1993) "Europeans and the European Community: The Dynamics of Public Support for European Integration." International Organization 47 (4) 507-34.

Eichenberg R and Dalton RJ (2007) "Post-Maastricht Blues: The Transformation of Citizen Support for European integration, 1973-2004." Acta Politica 42 (2-3): 128-52.

Etzioni A (1965) Political Unification: A Comparative Study of Leaders and Forces. New York: Holt Rinehart \& Winston.

Evans G, Carl N, and Dennison J (2018) "Brexit: The Causes and Consequences of the UK's Decision to Leave the EU”. In Europe's Crises, ed. Manuel Castells, Olivier Bouin, Joao Caraça, Gustavo Cardoso, John Thompson, Michel Wieviorka. New York: Wiley \& Sons.

Franklin MN and Wlezien C (1997) "The Responsive Public: Issue Salience, Policy Change, and Preferences for European Unification." Journal of Theoretical Politics 9 (3): 347-63.

Gabel M (1998) Interests and Integration: Market Liberalization, Public Opinion, and European Union. Ann Arbor: University of Michigan Press.

Gabel M and Anderson CJ (2002) "The Structure of Citizen Attitudes and the European Political Space." Comparative Political Studies 35 (8): 893-913.

Gabel M and Palmer HD (1995) "Understanding Variation in Public Support For European Integration." European Journal of Political Research 27 (1): 3-19.

Gabel M and Scheve K (2007) "Estimating the Effect of Elite Communications on Public Opinion Using Instrumental Variables.” American Journal of Political Science 51 (4): 1013-28.

Gaubatz KT (1995) "Intervention and Intransitivity: Public Opinion, Social Choice, and the Use of Military Force Abroad." World Politics 47 (4): 534-54.

Goertz G (2006) Social Science Concepts: A User's Guide. Princeton: Princeton University Press.

Haas EB (1968) The Uniting of Europe: Political, Social, and Economic Forces, 1950-1957. Palo Alto: Stanford University Press.

Hobolt SB and de Vries CE (2016) "Public Support for European Integration." Annual Review of Political Science 19:413-32

Hooghe L and Marks G (2005) "Calculation, Community and Cues: Public Opinion on European Integration." European Union Politics 6 (4): 419-43.

Hooghe L and Marks G (2007) "Sources of Euroscepticism." Acta Politica 42 (2-3): 119-27.

Inglehart, R and Rabier JR (1978) "Economic Uncertainty and European Solidarity: Public Opinion Trends." Annals of the American Academy of Political and Social Science 440 (1): 66-97. 
Inglehart R and Reif KH (1991) "Analyzing Trends in West European Opinion: The Role of the Eurobarometer Surveys.” In Eurobarometer: The Dynamics of European Public Opinion, ed. Karl-Heinz Reif and Ronald Inglehart. New York: St.Martin's Press.

Isernia P (2008) "Present At Creation: Italian Mass Support for European Integration in the Formative Years." European Journal of Political Research 47 (3): 383-410.

Janssen J (1991) "Postmaterialism, Cognitive Mobilization, and Public Support for European Integration." British Journal of Political Science 21 (4): 443-68.

Lindberg L and Scheingold S (1970) Europe's Would-Be Polity. Englewood Cliffs, NJ: Prentice Hall.

Loveless M and Rohrschneider R (2011) "Public Perceptions of the EU as a System of Governance." Living Reviews in European Governance 6 (2). Available at: http://www.livingreviews.org/lreg-2011-2. (accessed 28 April 2018)

McLaren LM (2006) Identity, Interests and Attitudes To European Integration. New York: Palgrave Macmillan.

Merritt RL and Puchala DJ (eds.) (1968) Western European Perspectives on International Affairs: Public Opinion Studies and Evaluations. New York: Frederick A. Praeger Publishers.

Moravcsik A (1998) The Choice for Europe: Social Purpose and State Power From Messina to Maastricht. Ithaca, NY: Cornell University Press.

Norris P (1999) “The Political Regime.” In Political Representation and Legitimacy in the European Union, ed. Hermann Schmitt and Jacques Thomassen. New York: Oxford University Press.

Pannico R (2017) “Is the European Union Too Complicated? Citizens' Lack of Information and Party Cue Effectiveness." European Union Politics 18 (3): 424-46.

Puchala DJ (1968) "Factor Analysis in International Survey Research.” In Western European Perspectives on International Affairs: Public Opinion Studies and Evaluations, ed. Richard Merritt and Donald J. Puchala. New York: Frederick A. Praeger Publishers.

Schmitt H and Thomassen JJ (2000) "Dynamic Representation: The Case of European Integration." European Union Politics 1 (3): 318-39.

Sartori G (1970) "Concept Misinformation in Comparative Politics.” American Political Science Review 64 (4): 1033-53.

Sinnott R (1995) “Policy, Subsidiarity, and Legitimacy.” In O. Niedermayer \& R. Sinnott (eds.) Public Opinion and Internationalized Governance. New York: Oxford University Press.

Soroka SN and Wlezien C (2010) Degrees of Democracy: The Public, Politics and Policy. Cambridge: Cambridge University Press.

Stimson JA (1991) Public Opinion in America: Moods, Cycles, and Swings. Boulder: Westview.

Stimson, JA (1999) Public Opinion in America: Moods, Cycles, and Swings, $2^{\text {nd }}$ Edition. Boulder, CO: Westview Press.

Stimson JA (2004) Tides of Consent: How Public Opinion Shapes American Politics. New York: Cambridge University Press.

Stimson JA (2005) "Policy Sentiment in the UK: Reflections on the 2005 Elections in Longitudinal Perspective." Paper presented at the Elections, Public Opinion and Parties 2005 Annual Conference, September 9-11, University of Essex.

Toshkov D (2011) "Public Opinion and Policy Output in the European Union: A Lost Relationship.” European Union Politics 12 (2): 169-91.

Wessels B (1995) "Evaluations of the EC: Elite or Mass-Driven?" In Public Opinion and Internationalized Governance, ed. Oskar Niedermayer and Richard Sinnott. New York: Oxford University Press.

Wessels B (2007) "Discontent and European Identity: Three Types of Euroscepticism." Acta Politica 42 (2-3): 287-306. 


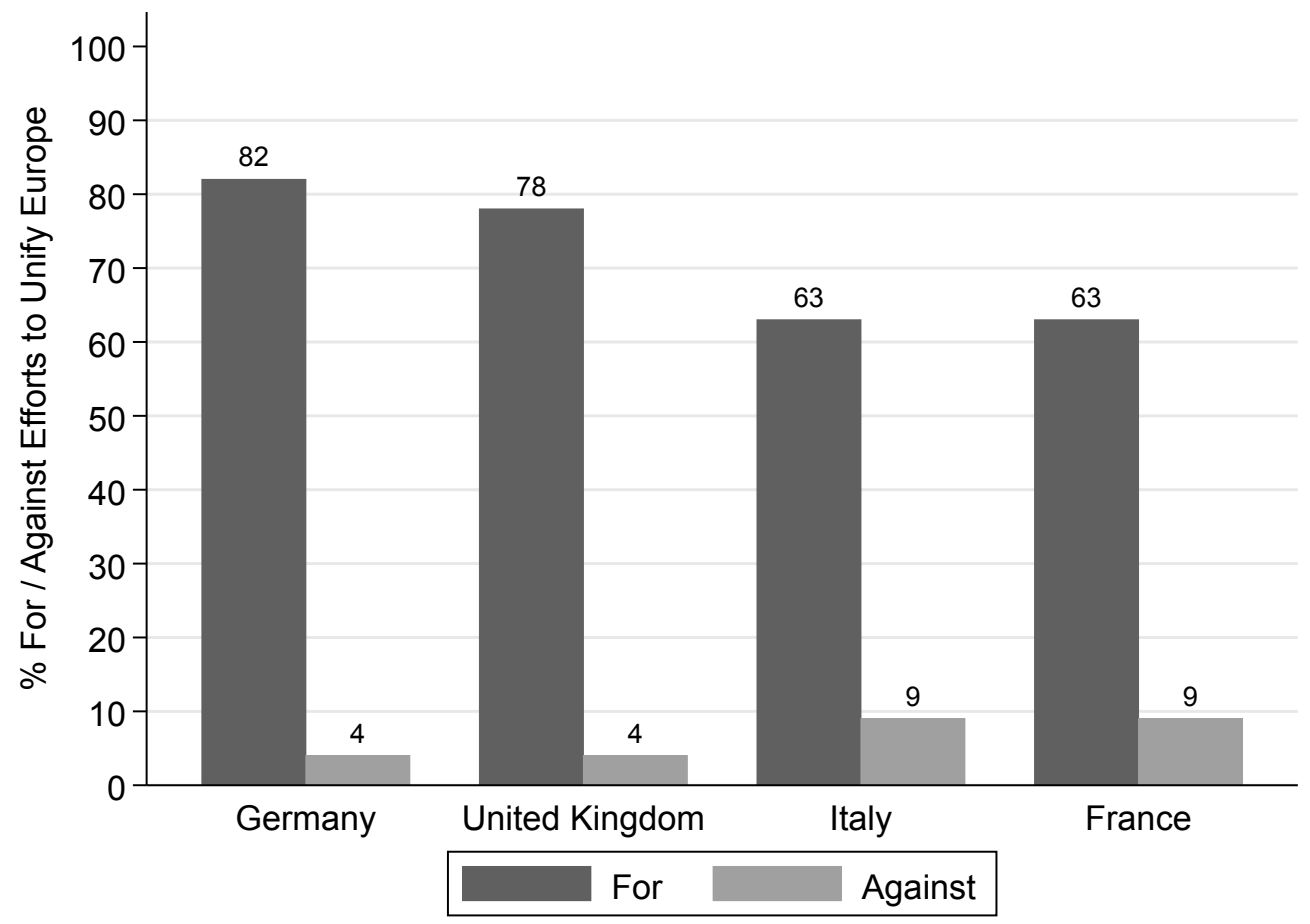

Figure 1. Attitudes Toward European Unification (October 1954 USIA Survey) 


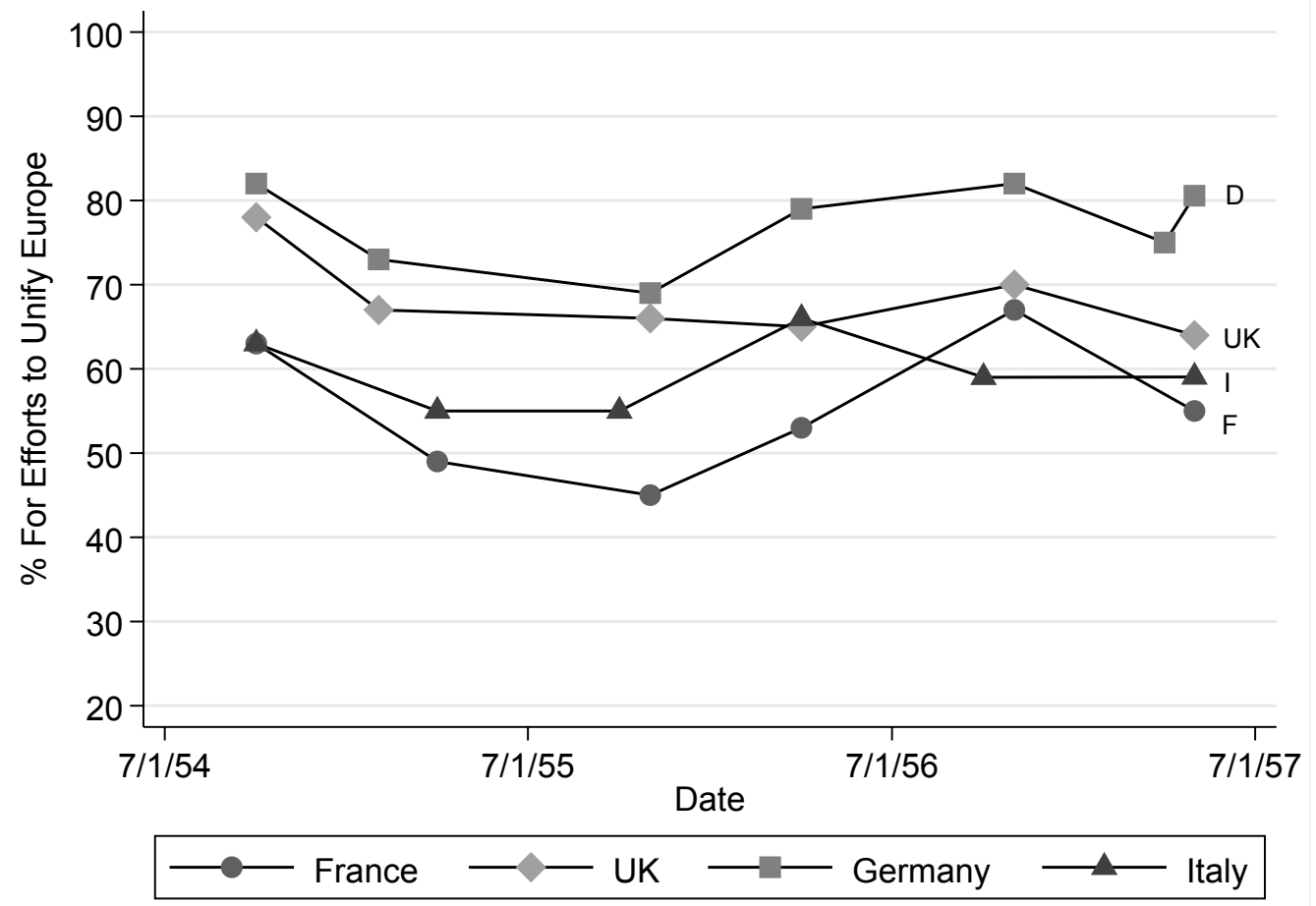

Figure 2. Support for European Unification,1954-57 (USIA Surveys, October 1954, February 1955, November 1955, April 1956, November 1956, May 1957, with fieldwork varying by country.) 

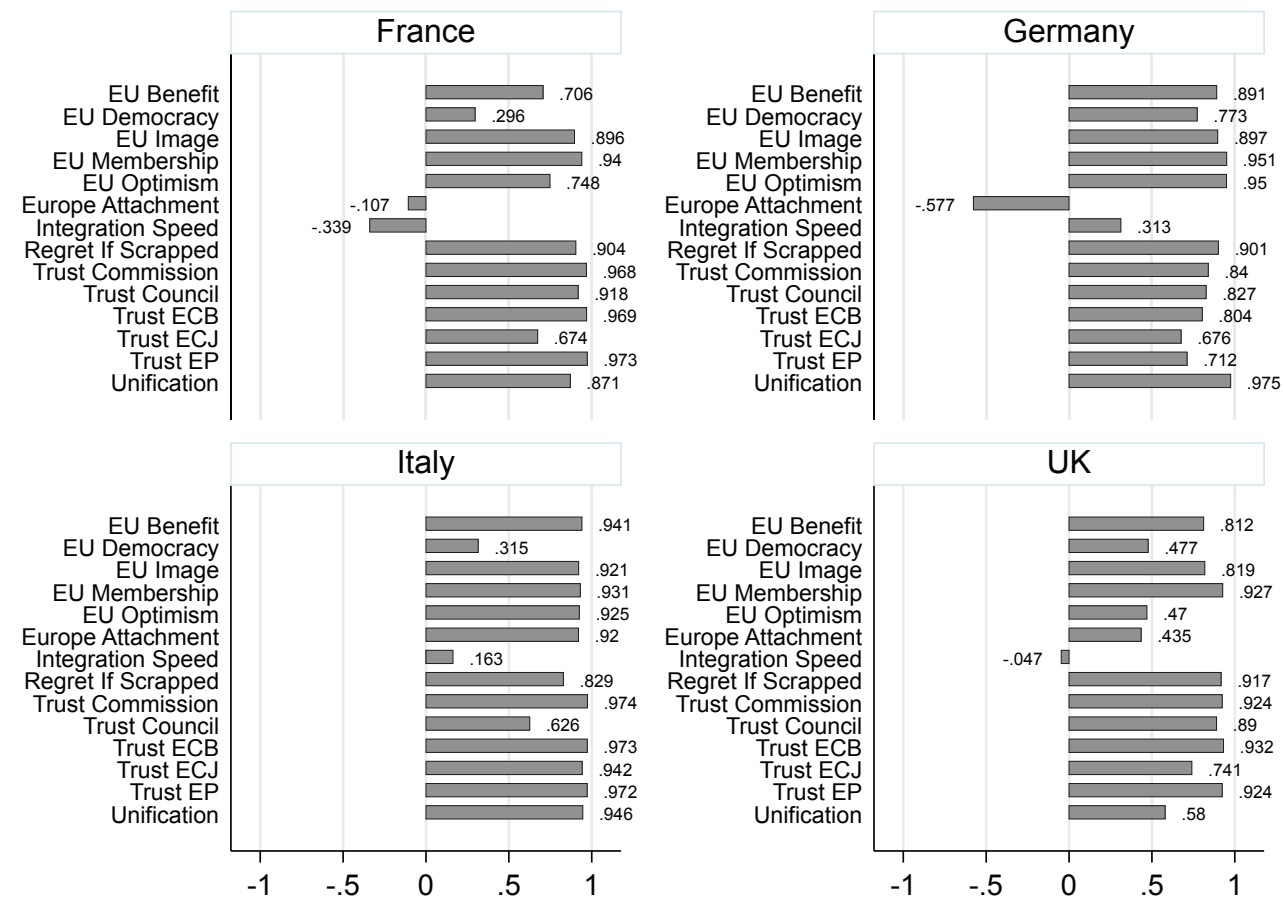

Figure 3. Preference For Europe Factor Loadings (1952-2017) 


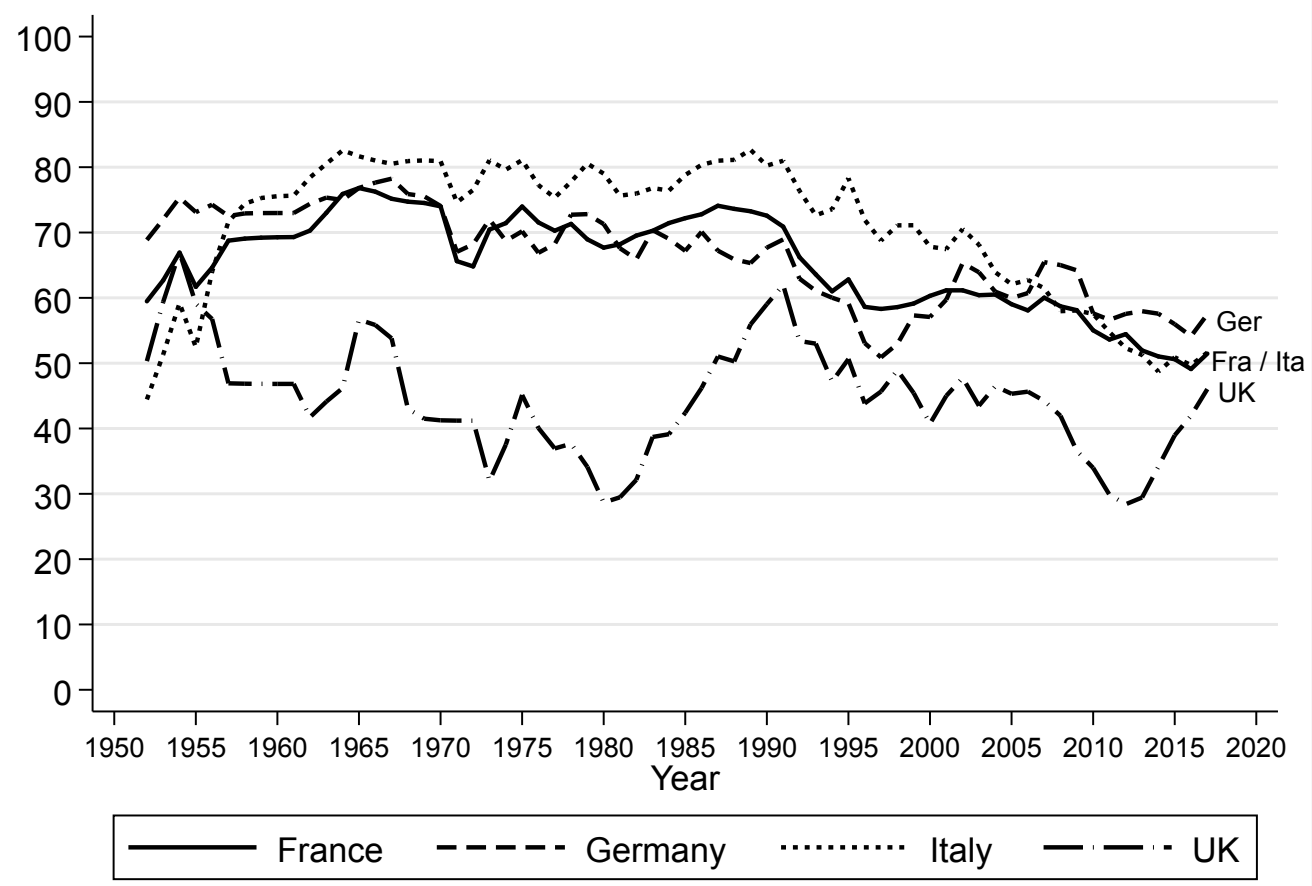

Source: Dyad ratios algorithm based on 14 survey items.

Figure 4. Public Support for European Integration in Four Countries, 1952-2017 

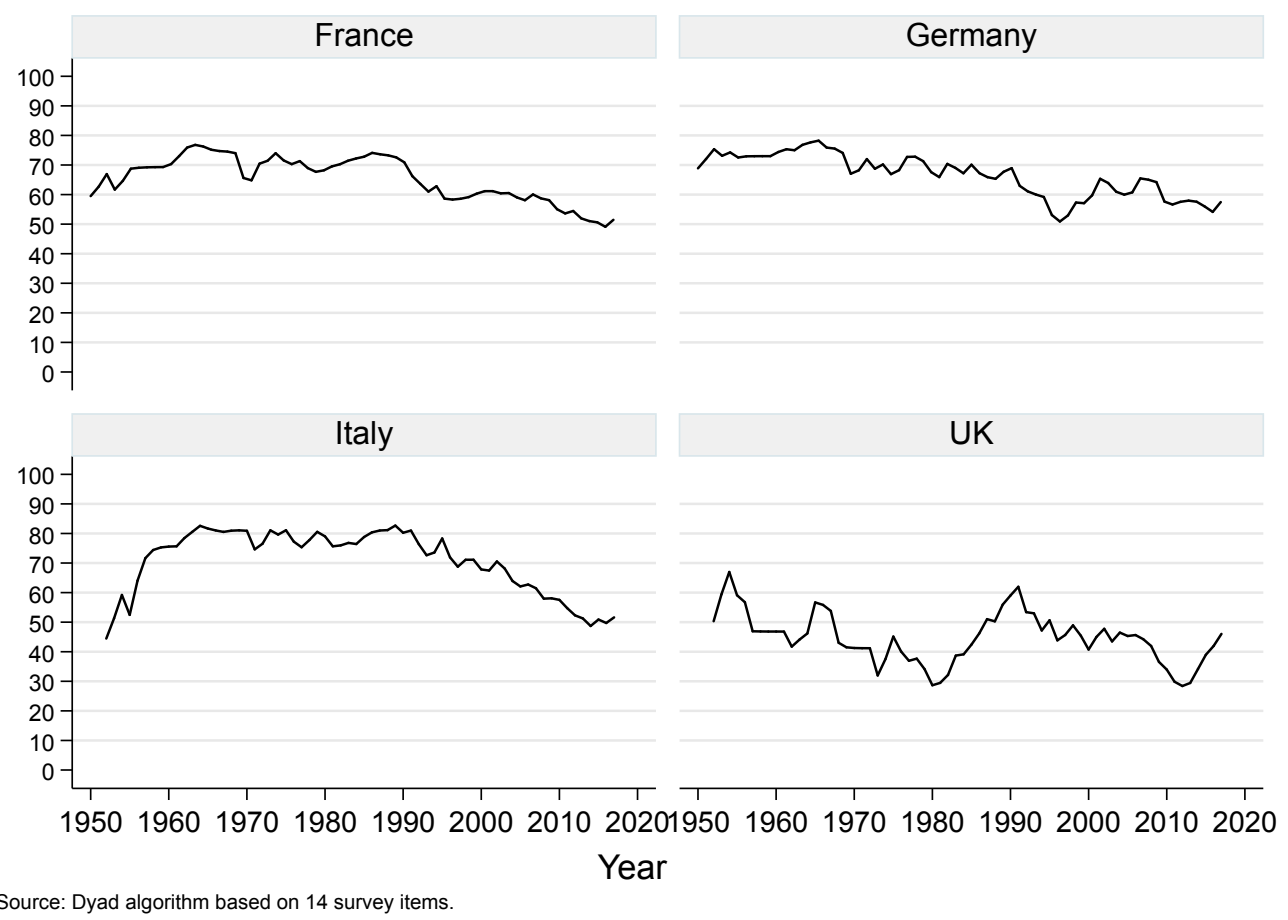

Figure 5. Preferences For Europe, 1952-2017 
Table 1. Dimensionality in Support for European Integration, 1952-2017

\begin{tabular}{|c|c|c|c|c|c|c|c|c|}
\hline \multirow[b]{3}{*}{ Period } & \multicolumn{2}{|c|}{ FRANCE } & \multicolumn{2}{|c|}{ GERMANY } & \multicolumn{2}{|c|}{ ITALY } & \multicolumn{2}{|c|}{ UK } \\
\hline & \multicolumn{2}{|c|}{ Factor } & \multicolumn{2}{|c|}{ Factor } & \multicolumn{2}{|c|}{ Factor } & \multicolumn{2}{|c|}{ Factor } \\
\hline & 1 & 2 & 1 & 2 & 1 & 2 & 1 & 2 \\
\hline $\begin{array}{l}\text { 1952-2017 } \\
\text { (all surveys) }\end{array}$ & $\begin{array}{c}\mathbf{2 . 8 4} \\
(66.0)\end{array}$ & $\begin{array}{c}0.73 \\
(16.9)\end{array}$ & $\begin{array}{c}\mathbf{3 . 0 3} \\
(70.6)\end{array}$ & $\begin{array}{c}0.53 \\
(12.4)\end{array}$ & $\begin{array}{c}\mathbf{3 . 2 1} \\
(74.6)\end{array}$ & $\begin{array}{c}0.69 \\
(16.0)\end{array}$ & $\begin{array}{c}2.54 \\
(60.7)\end{array}$ & $\begin{array}{c}0.78 \\
(18.6)\end{array}$ \\
\hline $\begin{array}{l}\text { 1973-2017 } \\
\text { (Eurobarometer) }\end{array}$ & $\begin{array}{l}4.06 \\
(67.9)\end{array}$ & $\begin{array}{c}\mathbf{1 . 0 1} \\
(17.0)\end{array}$ & $\begin{array}{c}4.17 \\
(69.9)\end{array}$ & $\begin{array}{c}0.58 \\
(9.81)\end{array}$ & $\begin{array}{c}4.34 \\
(72.5)\end{array}$ & $\begin{array}{c}\mathbf{1 . 0 5} \\
(17.5)\end{array}$ & $\begin{array}{c}3.64 \\
(61.9)\end{array}$ & $\begin{array}{c}0.85 \\
(14.5)\end{array}$ \\
\hline
\end{tabular}

Notes: Entries are Eigenvalue estimates. Eigenvalues $>1$ in bold. Numbers in parentheses indicate the $\%$ variance explained by each factor. Not all survey items are available or available in equal numbers during the two periods (1952-2017 and 1973-2017; see Table A.1 in the Online appendix). 
Table 2. Dimensionality in Support for European Integration, Pre- and Post-Maastricht

\begin{tabular}{lcccccccc} 
& \multicolumn{2}{c}{ FRANCE } & \multicolumn{2}{c}{ GERMANY } & \multicolumn{2}{c}{ ITALY } & \multicolumn{2}{c}{ UK } \\
\hline & \multicolumn{2}{c}{ Factor } & \multicolumn{2}{c}{ Factor } & \multicolumn{2}{c}{ Factor } & \multicolumn{2}{c}{ Factor } \\
Period & $\mathbf{1}$ & $\mathbf{2}$ & $\mathbf{1}$ & $\mathbf{2}$ & $\mathbf{1}$ & $\mathbf{2}$ & $\mathbf{1}$ & $\mathbf{2}$ \\
\hline $\begin{array}{l}\text { Pre- } \\
\text { Maastricht }\end{array}$ & & & & & & & & \\
& & & & & & & & \\
$1973-1991$ & $\mathbf{2 . 2 4}$ & 0.41 & $\mathbf{2 . 1 8}$ & 0.37 & $\mathbf{2 . 3 5}$ & 0.35 & $\mathbf{2 . 3 5}$ & 0.42 \\
& $(69.8)$ & $(12.9)$ & $(68.0)$ & $(11.4)$ & $(73.1)$ & $(11.0)$ & $(76.9)$ & $(13.8)$ \\
\hline
\end{tabular}

\section{Post-}

Maastricht

$\begin{array}{ccccccccc} & \mathbf{3 . 9 9} & \mathbf{1 . 7 3} & \mathbf{5 . 1 4} & \mathbf{1 . 1 3} & \mathbf{6 . 1 1} & \mathbf{1 . 0 2} & \mathbf{4 . 6 6} & \mathbf{1 . 0 8} \\ 1992-2017 & (49.8) & (21.6) & (64.5) & (14.1) & (76.4) & (12.8) & (58.8) & (13.6)\end{array}$

Notes: Entries are Eigenvalue estimates. Eigenvalues $>1$ in bold. Numbers in parentheses indicate the \% variance explained by each factor. Not all survey items are available or available in equal numbers during the two periods (1952-2017 and 1973-2017; see Table A.1 in the Online appendix). 